\title{
Association between daytime napping and obesity in Chinese middle-aged and older adults
}

\author{
Nan Wang ${ }^{1}$, Junyi Zou ${ }^{1}$, \\ Shu Fang ${ }^{2}$, Junmin Zhou ${ }^{1}$ \\ ${ }^{1}$ West China School of Public \\ Health and West China Fourth \\ Hospital, Sichuan University, \\ Chengdu, Sichuan, China \\ ${ }^{2}$ Department of Medicine, The \\ University of Hong Kong, Hong \\ Kong
}

Background No studies have assessed the association between daytime napping and obesity in China. The study aimed to examine the association between daytime napping and obesity among Chinese middle-aged and older adults, and to evaluate the difference between the aforementioned association in men and women.

Methods Overall, 14685 participants aged 45 years and older were included by using data from China Health and Retirement Longitudinal Study (CHARLS) in 2015. A multivariable logistic regression model was used to investigate the relationship between daytime napping and obesity after adjusting for potential confounders. Stratified analyses were performed to examine the association differences by sex. Besides, the Cochran-Armitage test for trend was used to detect if there was a significant dose-response relationship between daytime napping and obesity.

Results The mean age of participants was 60.32, and the mean daytime napping duration was 38.97 minutes. In the sample, compared with no daytime napping group, the risks of being obese were higher in both moderate daytime napping group (1-60 minute/d) (odds ratio $\mathrm{OR}=1.27,95 \%$ confidence interval $(\mathrm{CI})=1.13-1.44$ ) and extend long daytime napping group ( $>60$ minute/d) $(\mathrm{OR}=1.34,95 \% \mathrm{CI}=1.15-1.56)$. In sex stratification, these significant correlations only existed in women but not in men. Compared with no daytime napping, women who napped 1-60 minute/d and over 60 minute/d were more likely to be obese $(\mathrm{OR}=1.37,95 \% \mathrm{CI}=1.18-1.59$ and $\mathrm{OR}=1.49$, 95\% CI $=1.23-1.81$, respectively). Besides, the Cochran-Armitage trend test revealed that the prevalence rate of obesity increased as the daytime napping duration increased $(P<0.001)$.

Conclusions The study established the relationship between daytime napping and obesity in a general Chinese population. The association, however, was only detected among women. Furthermore, there was a dose-response relationship between daytime napping and obesity among women. Future studies may verify this association by using a longitudinal design and focus on the mechanisms behind such association.

\section{Correspondence to:}

Junmin Zhou PhD

West China School of Public Health and West China Fourth Hospital

Sichuan University

Chengdu

China

junmin.zhou@scu.edu.cn
Obesity is one of the most significant public health concerns in the world [1]. It was estimated that obesity prevalence in adults was 603.7 million in 2015 globally [2]. Obesity leads to great external costs to society, and the global costs of obesity were evaluated to be $2.8 \%$ gross domestic product or 2.0 trillion dollars in $2014[3,4]$. In China alone, because of the rapid economic growth, urbanization and changes in lifestyle, the overall obesity rate was over $20 \%$ in some areas [5]. Also, being obese is related to many health issues, such as diabetes [6], cardiovascular disease [7], several cancers [8], even reducing life quality and expectancy. 
Daytime napping is a common behavior in many countries and the prevalence of daytime napping ranges from $10 \%$ to $68.6 \%$ in different groups [9-11]. It is widespread in China, too. Many Chinese regards it as a traditional and healthy lifestyle and as part of planned and regular routine across all age groups [12-14]. A large number of studies, however, have found the negative impacts of daytime napping on health outcomes. Specifically, those who napped over 1 hour/d had a 31\% increased risk of developing diabetes [15]. Longer daytime napping was associated with an increased risk of hypertension [16]. A significantly positive association was examined between daytime napping and depression among 45-65 years old in both sexes [17]. Extended daytime napping was positively associated with a higher risk of stroke [18]. However, only three studies have examined the relationship between daytime napping and obesity. Two of them found daytime napping was significantly associated with obesity, while another reported insignificant association. Specifically, both of the significant studies came from the United States. One of them showed that daytime napping increased $10.4 \%$ of prevalence of obesity among participants aged 18-64 years [19], and the other one indicated daytime napping was associated with obesity in older populations (male and female participants were from two distinct cohorts) [20]. Another study in Japan found the insignificance of napping duration and obesity among the oldest population (aged $\geq 80$ years) [21]. In addition to the inconsistent findings, the specification and categorization of napping in the above studies (eg, more than one 15-minute nap per week was regarded as napping) were not comparable to mainstream napping studies, as daytime napping was not their primary research focus. Hence, it appears to be necessary to conduct a study with an overarching goal focusing on daytime napping and obesity. Furthermore, no studies have evaluated such association in China. Thus, the primary research objective of the study was to investigate the association between daytime napping and obesity in middle-aged and older Chinese adults by using a nationally representative sample.

Besides, previous studies have shown the disparity in obesity or daytime napping in different sex groups [22-24], so the secondary objective was to examine the sex difference in the relationship between daytime napping and obesity.

\section{METHODS}

\section{Study design and population}

The cross-sectional data of China Health and Retirement Longitudinal Study (CHARLS) in 2015 were used. CHARLS, as an ongoing open cohort on 45 years or above of age, started in 2011, followed up with participants every 2 years, and covered 28 provinces in China. CHARLS chose multistage probability sampling to evaluate the economic, social and health status of middle-aged and elderly Chinese people. Data were collected by face-to-face computer-assisted personal interviews. Details of CHARLS can be accessed elsewhere [25].

The secondary data from CHARLS could be downloaded publicly on http://charls.pku.edu.cn/en. The total participants were under investigation with the permission of informed consent. The ethical approval of data collection was from the Biomedical Ethics Review Committee of Peking University (IRB0000105211015) [26].

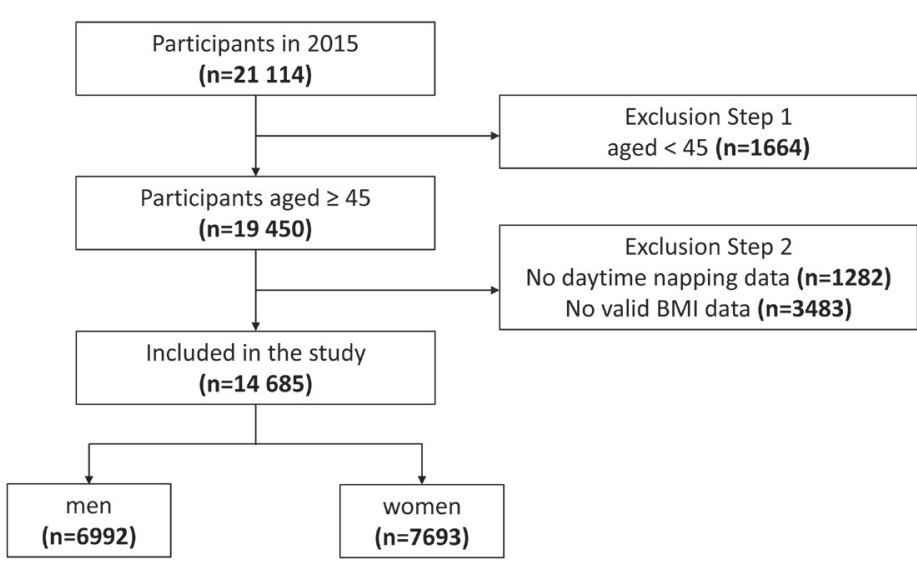

Figure 1. Sample included in the study.
Figure 1 shows the data inclusion flowchart. In 2015, 21144 participants were investigated, and the final number of the population included in this study was 14 685, including 6992 men and 7693 women. Exclusion criteria followed these steps: (1) age less than 45 years, (2) missing values of daytime napping, (3) no valid Body Mass Index (BMI) data.

To understand the possible impacts of step 2 exclusion, we compared our final sample with the sample before step 2 exclusion (ie, exclusion based on invalid data of BMI and napping) (Table S1 in the Online Supplementary Document).

Our final sample was not largely different from the sample before step 2 exclusion in many aspects, although the hypertension prevalence was higher in 
the final sample than that in the sample before exclusion (30.7\% vs $23.3 \%$ ). Thus, the exclusion of those samples based on invalid data of BMI and napping would not pose a grave concern.

\section{Measurements}

\section{Obesity}

BMI was calculated as the weight in kilograms divided by the height in meters squared, $\mathrm{kg} / \mathrm{m}^{2}$. Because of the different body shapes and skeletons among Chinese [27], the criteria for the BMI was adopted according to the National Health and Family Planning Commission of the People's Republic of China [28]. Particularly, it has four categories: under-weight $\left(<18.5 \mathrm{~kg} / \mathrm{m}^{2}\right)$, normal-weight $\left(18.5-23.9 \mathrm{~kg} / \mathrm{m}^{2}\right)$, overweight $\left(24.0-27.9 \mathrm{~kg} / \mathrm{m}^{2}\right)$ and obesity $\left(\geq 28.0 \mathrm{~kg} / \mathrm{m}^{2}\right)$. In our study, obesity was defined as BMI $\geq 28.0 \mathrm{~kg} / \mathrm{m}^{2}$, while non-obesity was $\mathrm{BMI}<28.0 \mathrm{~kg} / \mathrm{m}^{2}$.

\section{Daytime napping}

Self-reported daytime napping duration was obtained by asking the question "During the past month, how long did you generally take a nap after lunch?" According to the previous literature [22,29], the outcomes on daytime napping were classified into three groups: 0 minute/d (no daytime napping), 1-60 minute/d (moderate daytime napping) and >60 minute/d (extended daytime napping).

\section{Covariates}

Covariates were constituted by three groups: demographic and socio-economic status, health behaviors, and health-related variables. Demographic and socio-economic status included age, community type, sex, marital status, education, annual household income and employment. Health behaviors were comprised of alcohol consumption, smoking, nighttime sleep, sleep quality and physical activity. Health-related variables included diagnosed hypertension and diabetes.

Community type was defined as "urban" (main city zone/combination zone between urban and rural areas/the town center/ZhenXiang area/special area) and "rural" (township central/village) [22]. Education was divided into "no formal education (illiterate) or did not finish primary school", "Sishu/home school/ elementary school", and "middle school or above". Marital status was classified into "cohabited" (married with spouse present/cohabitated) and "other" (married but not living with spouse temporarily for reasons/separated/divorced/widowed/never married). Annual household income was separated into three groups, 0 to 4000, 4001 to 25 000, and over $25000 \mathrm{CNY}$, and the exchange rate between CNY and US dollar was 6.2 in 2015 (6.2 CNY - 1 US dollar). To complete the annual household income data, the way of linear interpolation was used to obtain all components of household income.

Alcohol consumption was divided into "yes" (drink more than once a month/drink but less than once a month) and "no". Similarly, smoking was "yes" (current/former smokers) and "no". Nighttime sleep was categorized by the question "during the past month, how many hours of actual sleep did you get at night (average hours for per night) (this may be shorter than the number of hours you spend in bed)". By asking the question "my sleep was restless", four options of "rarely or none the time ( $<1$ day)", "some or a little of the time (1-2 days)", "occasionally or a moderate amount of the time (3-4 days)", and "most or all of the time (5-7 days)" were represented as good, fair, poor and bad sleep quality, respectively. Physical activity was categorized into the binary variable as "yes" (walking or activities needing hard/high/moderate intensity physical effort for at least 10 minutes continuously during a usual week) and "no" [12,30]. Hypertension and diabetes were based on self-reported data.

\section{Analysis}

In the descriptive analyses, mean (standard deviation, SD) and frequency (percentage) for the continuous variables and categorical variables were used, respectively. Multivariable logistic regressions were adopted to explore the association between daytime napping and obesity, after adjusting for potential confounders, including age, sex, community type, marital status, annual household income, education, employment, smoking, alcohol consumption, nighttime sleep, sleep quality, physical activity, hypertension, and diabetes. The list-wise deletion was used in the regressions for those covariates with missing values. In addition, the Cochran-Armitage test for trend was used to detect if there was a significant dose-response relationship between daytime napping and obesity. Furthermore, in order to examine the possible difference of the aforementioned association in men and women, multivariable logistic regressions were conducted separately by sex. Odds ratios (ORs) and $95 \%$ confidence intervals (CI) were reported. All statistical 
analyses were 2-sided, and the P-value less than .05 could be identified as statistical significance. SPSS for Windows (version 21.0, IBM, New York, USA) was used to complete statistical processes of descriptive and multivariable logistic regression. Trend analysis was performed by R-3.6.3.

\section{RESULTS}

\section{Sample description}

The descriptive details of all included variables are displayed in Table $\mathbf{1}$. The total sample had a mean age of $60.32(\mathrm{SD}= \pm 9.66)$. The daytime napping duration was $38.97(\mathrm{SD}= \pm 45.14)$ minutes (including people who don't nap). Moreover, the proportion of daytime napping were $42.2 \%$ (0 minute/d), 39.1\% (1-60 minute/d), and 18.8\% (>60 minute/d). The overall obesity prevalence was $12.8 \%$.

In terms of sex differences, men appeared to nap more than their women counterparts (43.98\% vs $34.42 \%)$, while less likely to be obese (10.1\% vs $15.3 \%$ ).

\section{Association between daytime napping and obesity}

Table 2 indicates the multivariable logistic regression results on daytime napping and obesity after adjusting for covariates in the overall sample, men and women. As for the overall sample, the participants who took naps showed higher odds of being obese compared with the no daytime napping counterparts. The ORs in 1-60 minute/d and > $60 \mathrm{~min} / \mathrm{d}$ nap groups were 1.27 (95\% CI=1.13-1.44) and 1.34 (95\% $\mathrm{CI}=1.15-1.56)$. Stratified by sex, no significant relationship was found on daytime napping and obesity among men. However, compared to no daytime napping, the women with daytime napping had a higher probability of obesity in 1-60 minute/d group (OR=1.37, 95\% CI =1.18-1.59) and $>60 \mathrm{~min} / \mathrm{d}$ group $(\mathrm{OR}=1.49,95 \% \mathrm{CI}=1.23-1.81)$. In addition, the Cochran-Armitage trend test suggested that the longer women participants napped, the higher risk of obesity $(P<0.001)$. Figure 2 displayed the dose-response relationship between obesity percentage and different daytime napping group among women.

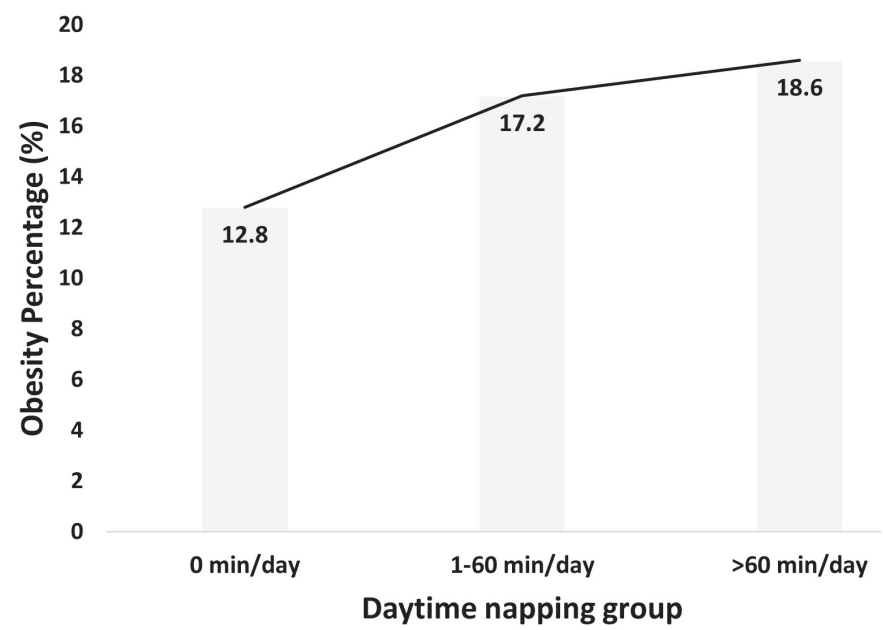

Figure 2. Obesity percentage by daytime napping group among women.

\section{DISCUSSION}

The study examined the association between daytime napping and obesity among men and women aged 45 years or above in China by using the cross-sectional data of CHARLS in 2015. Overall, the results suggested a significant association between daytime napping and obesity in the population. In addition, the disparity in daytime napping and obesity between sexes revealed a statistically significant association in women but not in men.

In our study, the prevalence of being obese among the overall sample was $12.8 \%$, and it was higher in women $(15.3 \%)$ than in men $(10.1 \%)$. This was consistent with a previous CHARLS study conduct- 
Table 1. Characteristics of sample

\begin{tabular}{|c|c|c|c|}
\hline & Overall sample & MeN & WoMEN \\
\hline VARIABIE & $\begin{array}{c}\text { Mean } \pm \text { SD or frequency } \\
(\text { percentage })\end{array}$ & $\begin{array}{c}\text { Mean } \pm \text { SD or frequency } \\
(\text { percentage })\end{array}$ & $\begin{array}{c}\text { Mean } \pm \text { SD or frequency } \\
\text { (percentage) }\end{array}$ \\
\hline \multicolumn{4}{|l|}{ Dependent variable } \\
\hline \multicolumn{4}{|l|}{ Obesity $(n=14685)$} \\
\hline No & $12803(87.2)$ & $6289(89.9)$ & $6514(84.7)$ \\
\hline Yes & $1882(12.8)$ & $703(10.1)$ & $1179(15.3)$ \\
\hline \multicolumn{4}{|l|}{ Independent variables } \\
\hline \multicolumn{4}{|c|}{ Demographic and socio-economic status } \\
\hline Age $(n=14685)$ & $60.32 \pm 9.66$ & $60.86 \pm 9.68$ & $59.83 \pm 9.62$ \\
\hline \multicolumn{4}{|c|}{ Community type $(n=14647)$ : } \\
\hline Rural & $10928(74.6)$ & $5224(74.8)$ & $5704(74.4)$ \\
\hline Urban & $3719(25.4)$ & $1760(25.2)$ & $1959(25.6)$ \\
\hline $\operatorname{Sex}(n=14685)$ & & $6992(47.6)$ & $7693(52.4)$ \\
\hline \multicolumn{4}{|l|}{ Marital status $(\mathrm{n}=14685)$ : } \\
\hline Other & $2540(17.3)$ & $917(13.1)$ & $1623(21.1)$ \\
\hline Cohabited & $12145(82.7)$ & $6075(86.9)$ & $6070(78.9)$ \\
\hline \multicolumn{4}{|l|}{ Education $(n=13514)$ : } \\
\hline Illiterate & $6078(45.0)$ & $1925(30.1)$ & $4153(58.3)$ \\
\hline Primary school & $3077(22.8)$ & $1766(27.7)$ & $1311(18.4)$ \\
\hline Middle school or above & $4359(32.3)$ & $2695(42.2)$ & $1664(23.3)$ \\
\hline \multicolumn{4}{|c|}{ Annual household income $(n=14685)$ : } \\
\hline $0-4000$ & $4830(32.9)$ & $2289(32.7)$ & $2541(33.0)$ \\
\hline $4001-25000$ & $4904(33.4)$ & $2340(33.5)$ & $2564(33.3)$ \\
\hline$>25000$ & $4951(33.7)$ & $2363(33.8)$ & $2588(33.6)$ \\
\hline \multicolumn{4}{|l|}{ Employment $(\mathrm{n}=14673)$ : } \\
\hline No & $4647(31.7)$ & $1758(25.2)$ & $2889(37.6)$ \\
\hline Yes & $10026(68.3)$ & $5231(74.8)$ & $4795(62.4)$ \\
\hline \multicolumn{4}{|l|}{ Health behaviors } \\
\hline \multicolumn{4}{|c|}{ Daytime napping $(\mathrm{n}=14685)$ : } \\
\hline $0 \mathrm{~min}$ & $6192(42.2)$ & $2594(37.1)$ & $3598(46.8)$ \\
\hline $1-60 \mathrm{~min}$ & $5736(39.1)$ & $2851(40.8)$ & $2885(37.5)$ \\
\hline$>60 \mathrm{~min}$ & $2757(18.8)$ & $1547(22.1)$ & $1210(15.7)$ \\
\hline \multicolumn{4}{|c|}{ Alcohol consumption $(n=14677)$ : } \\
\hline No & $9464(64.5)$ & $2929(41.9)$ & $6535(85.0)$ \\
\hline Yes & $5213(35.5)$ & $4057(58.1)$ & $1156(15.0)$ \\
\hline \multicolumn{4}{|l|}{ Smoking $(n=14666)$ : } \\
\hline No & $8275(56.4)$ & $1268(18.2)$ & $7007(91.1)$ \\
\hline Yes & $6391(43.6)$ & $5706(81.8)$ & $685(8.9)$ \\
\hline \multicolumn{4}{|c|}{ Nighttime sleep (hours) $(n=14510)$ : } \\
\hline$<6$ & $4425(30.5)$ & $1809(26.0)$ & $2616(34.6)$ \\
\hline $6-8$ & $8676(59.8)$ & $4510(64.9)$ & $4166(55.1)$ \\
\hline$>8$ & $1409(9.7)$ & $629(9.1)$ & $780(10.3)$ \\
\hline \multicolumn{4}{|l|}{ Sleep quality $(\mathrm{n}=14599)$ : } \\
\hline Good & $7545(51.7)$ & $4165(59.8)$ & $3380(44.3)$ \\
\hline Fair & $2036(13.9)$ & $960(13.8)$ & $1076(14.1)$ \\
\hline Poor & $2061(14.1)$ & $768(11.0)$ & $1293(16.9)$ \\
\hline $\mathrm{Bad}$ & $2957(20.3)$ & $1072(15.4)$ & $1885(24.7)$ \\
\hline \multicolumn{4}{|c|}{ Physical activity $(\mathrm{n}=14685)$} \\
\hline No & $8146(55.5)$ & $3862(55.2)$ & $4284(55.7)$ \\
\hline Yes & $6539(44.5)$ & $3130(44.8)$ & $3409(44.3)$ \\
\hline \multicolumn{4}{|l|}{ Health-related variables } \\
\hline \multicolumn{4}{|c|}{ Hypertension $(\mathrm{n}=14671)$ : } \\
\hline No & $10163(69.3)$ & $4923(70.5)$ & $5240(68.2)$ \\
\hline Yes & $4508(30.7)$ & $2060(29.5)$ & $2448(31.8)$ \\
\hline \multicolumn{4}{|l|}{ Diabetes $(n=14672)$ : } \\
\hline No & $13281(90.5)$ & $6408(91.7)$ & $6873(89.4)$ \\
\hline Yes & $1391(9.5)$ & $577(8.3)$ & $814(10.6)$ \\
\hline
\end{tabular}

SD - standard deviation, min - minute 
Table 2. Multivariable logistic regression on association between daytime napping and obesity*

\begin{tabular}{|c|c|c|c|}
\hline \multirow{2}{*}{ VARIABLE } & OVERALL SAMPLE ( $(\mathrm{N}=14 \mathrm{685})$ & MEN ( $=6992)$ & Women ( $(n=7693)$ \\
\hline & Odds ratio $(95 \% \mathrm{CI})$ & Odds ratio $(95 \% \mathrm{CI})$ & Odds ratio $(95 \% \mathrm{CI})$ \\
\hline \multicolumn{4}{|l|}{ Variables of interest } \\
\hline \multicolumn{4}{|c|}{ Daytime napping (minutes): } \\
\hline 0 (Ref) & 1 & 1 & 1 \\
\hline $1-60$ & $1.27(1.13-1.44)$ & $1.10(0.90-1.34)$ & $1.37(1.18-1.59)$ \\
\hline$>60$ & $1.34(1.15-1.56)$ & $1.13(0.90-1.44)$ & $1.49(1.23-1.81)$ \\
\hline \multicolumn{4}{|c|}{ Demographics and socioeconomic status } \\
\hline Age & $0.95(0.94-0.96)$ & $0.95(0.94-0.96)$ & $0.95(0.94-0.96)$ \\
\hline \multicolumn{4}{|l|}{ Community type: } \\
\hline Rural (Ref) & 1 & 1 & 1 \\
\hline Urban & $1.30(1.14-1.48)$ & $1.40(1.14-1.72)$ & $1.24(1.05-1.47)$ \\
\hline \multicolumn{4}{|l|}{ Sex: } \\
\hline Men & 1 & - & - \\
\hline Women & $1.24(1.04-1.47)$ & - & - \\
\hline \multicolumn{4}{|l|}{ Marital status: } \\
\hline Other (Ref) & 1 & 1 & 1 \\
\hline Cohabited & $1.18(1.01-1.37)$ & $1.55(1.14-2.10)$ & $1.07(0.89-1.28)$ \\
\hline \multicolumn{4}{|l|}{ Education: } \\
\hline Illiterate (Ref) & 1 & 1 & 1 \\
\hline Primary School & $0.86(0.74-0.99)$ & $0.89(0.70-1.14)$ & $0.87(0.72-1.05)$ \\
\hline Middle school or above & $0.92(0.81-1.06)$ & $1.02(0.81-1.28)$ & $0.87(0.73-1.04)$ \\
\hline \multicolumn{4}{|c|}{ Annual household income: } \\
\hline $0-4000$ (Ref) & 1 & 1 & 1 \\
\hline $4001-25000$ & $1.02(0.89-1.17)$ & $1.12(0.90-1.40)$ & $0.96(0.81-1.14)$ \\
\hline$>25000$ & $0.96(0.84-1.11)$ & $1.03(0.82-1.30)$ & $0.91(0.77-1.09)$ \\
\hline \multicolumn{4}{|l|}{ Employment: } \\
\hline No (Ref) & 1 & 1 & 1 \\
\hline Yes & $0.73(0.64-0.82)$ & $0.79(0.63-0.99)$ & $0.69(0.59-0.80)$ \\
\hline
\end{tabular}

Health behavior

Alcohol consumption:

\begin{tabular}{|c|c|c|c|}
\hline No (Ref) & 1 & 1 & 1 \\
\hline Yes & $0.82(0.72-0.94)$ & $0.84(0.70-1.01)$ & $0.76(0.62-0.94)$ \\
\hline \multicolumn{4}{|l|}{ Smoking: } \\
\hline No (Ref) & 1 & 1 & 1 \\
\hline Yes & $0.82(0.69-0.97)$ & $0.75(0.61-0.92)$ & $0.94(0.73-1.21)$ \\
\hline \multicolumn{4}{|c|}{ Nighttime sleep (hours): } \\
\hline$<6$ (Ref) & 1 & 1 & 1 \\
\hline $6-8$ & $1.08(0.95-1.23)$ & $1.08(0.86-1.35)$ & $1.08(0.92-127)$ \\
\hline$>8$ & $1.16(0.95-1.43)$ & $1.14(0.80-1.62)$ & $1.18(0.92-1.52)$ \\
\hline \multicolumn{4}{|c|}{ Sleep quality: } \\
\hline Good (Ref) & 1 & 1 & 1 \\
\hline Fair & $0.97(0.82-1.14)$ & $1.04(0.81-1.33)$ & $0.92(0.75-1.14)$ \\
\hline Poor & $0.94(0.80-1.10)$ & $0.89(0.67-1.18)$ & $0.96(0.79-1.16)$ \\
\hline $\mathrm{Bad}$ & $0.83(0.71-0.98)$ & $0.78(0.58-1.03)$ & $0.85(0.70-1.03)$ \\
\hline \multicolumn{4}{|c|}{ Physical activity: } \\
\hline No (Ref) & 1 & 1 & 1 \\
\hline Yes & $1.02(0.92-1.13)$ & $1.12(0.95-1.34)$ & $0.96(0.83-1.10)$ \\
\hline \multicolumn{4}{|c|}{ Health-related variables: } \\
\hline \multicolumn{4}{|c|}{ Hypertension: } \\
\hline No (Ref) & 1 & 1 & 1 \\
\hline Yes & $3.15(2.81-3.52)$ & $3.34(2.80-4.00)$ & $1.25(1.02-1.52)$ \\
\hline \multicolumn{4}{|l|}{ Diabetes: } \\
\hline No (Ref) & 1 & 1 & 1 \\
\hline Yes & $1.31(1.12-1.53)$ & $1.41(1.08-1.83)$ & $3.02(2.62-3.48)$ \\
\hline
\end{tabular}

SD - standard deviation, CI - confidence interval

*Bold values represent statistical significance. 
ed in 2011 . The corresponding obesity rates were $11.38 \%, 14.28 \%$ and $8.16 \%$ in the total sample, women and men, respectively [31]. Further, the prevalence showed a slight upward trend, indicating obesity is on the rise in China, which was in line with the recent analyses [32,33]. Of all participants, $57.8 \%$ had reported daytime napping habits. Daytime napping was more prevalent in men, and the mean napping duration in women is shorter than that in men. This is in line with previous studies, which found that men were more likely to nap and longer daytime napping was more common in men than women $[14,23]$.

Our study found a significant positive association between daytime napping and obesity. In the population of middle-aged and older Chinese, the probability of being obese was comparatively higher in those with daytime napping habits. This was partially in accordance with previous studies. As mentioned earlier, one study found daytime napping was associated with higher obesity risk, which included the population aged 18-64 [19]. In another study focusing on the oldest population (aged $\geq 80$ ), however, the relationship was insignificant [21]. The disparity could be due to the different age ranges of research populations.

Further, sex disparity in daytime napping and obesity was observed. The statistically significant correlation between daytime napping and obesity only existed in women. Compared to not taking naps, women with daytime napping were associated with a higher probability of being obese. A previous study suggested that daytime napping increased the risk of being obese in both older men ( $O R=1.23)$ and women $(\mathrm{OR}=1.29)$ [20]. One possible reason for the inconsistent conclusion could be that populations in that study came from different studies and time periods, which makes the results not comparable. Furthermore, with the increase in daytime napping, the percentage of obesity in women increased. Specifically, compared with women who did not nap, the risk of obesity in extended daytime napping group ( $>60$ minute/d) was higher than it in moderate daytime napping group (1-60 minute/d). This finding not only underscores the deteriorating effects of napping, but also suggests daytime napping as a potential target in obesity prevention and control programs in women.

The biological mechanisms underlying the link of daytime napping and obesity in women remain not fully clear. Several hypotheses could be proposed. First, the sympathetic nervous system (SNS) can be activated after stimulation by daytime napping, and SNS is positively correlated with obesity, therefore daytime napping may affect obesity status through the sympathetic nervous system [29,34]. Then, daytime napping can extend bedtime, so that the decreased thermogenesis and energy expenditure may result in obesity $[35,36]$. Finally, previous studies found that daytime napping and depression have a significantly positive association, and depressive symptoms are associated with decreasing estradiol levels during the transition to menopause [17,37]. Meanwhile, the significant association between menopause and obesity has been established [38]. Therefore, the menopause may have played a vital role in the relationship between daytime napping and obesity. The first two hypotheses mentioned above help to explain the biologic mechanism on the relationship between daytime napping and obesity, and the last one is useful to understand why middle-aged and older women were more likely to be obese. All the hypotheses may provide cues for exploring biological mechanisms underlying the association.

There are several limitations to the study. First, this was a cross-sectional study, the causal inference might not be concluded between daytime napping and obesity. Second, the self-reported daytime napping data might result in recall bias. Third, a large number of cases were removed in our study due to invalid data of BMI and napping. Although the exclusion of those cases did not dramatically change the profile of our samples (Table S1 in the Online Supplementary Document), the hypertension prevalence was higher in the final sample than that in the sample before exclusion (30.7\% vs $23.3 \%$ ). Caution thus should be used when interpreting our findings. Last, participants from the study were all Chinese, and it might not be representative of other groups globally. However, our study still has some strengths: (1) it was the first study to focus on the association daytime napping and obesity in middle-aged and older people in China, (2) it had a large population size and was nationally representative, (3) it found that women who napped were at a higher risk of being obese, which may provide evidence to guide future research.

\section{CONCLUSIONS}

The findings in the study revealed the significant association between daytime napping and obesity. This association, however, only existed in middle-aged and older women. Future studies may verify this association by using a longitudinal design and focus on the mechanisms behind such association. 


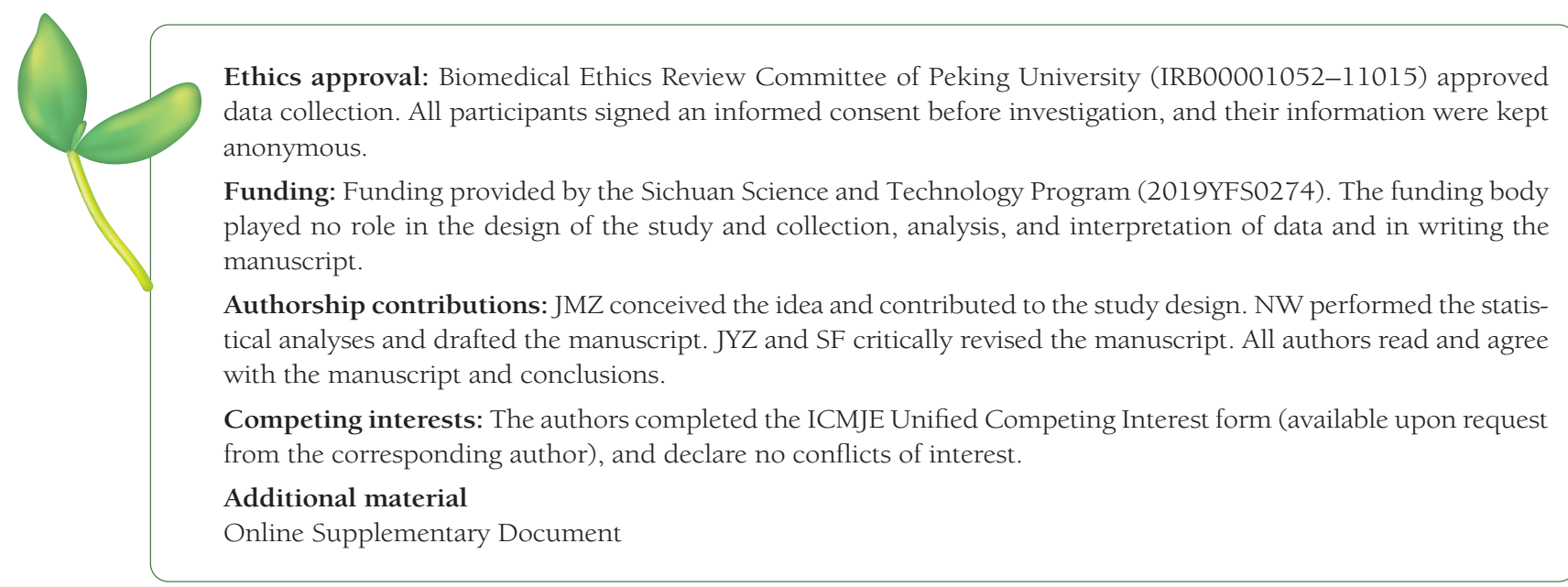

1 Natsis M, Antza C, Doundoulakis I, Stabouli S, Kotsis V. Hypertension in Obesity: Novel Insights. Curr Hypertens Rev. 2020;16:30-6. Medline:30987571 doi:10.2174/1573402115666190415154603

2 Collaborators GO, Afshin A, Forouzanfar MH, Reitsma MB, Sur P, Estep K, et al. Health effects of overweight and obesity in 195 countries over 25 years. N Engl J Med. 2017;377:13-27. Medline:28604169 doi:10.1056/NEJMoal614362

3 Parks JC, Alston JM, Okrent AM. The Marginal External Cost of Obesity in the United States. 2012.

4 Dobbs R, Sawers C, Thompson F, Manyika J, Woetzel J, Child P, et al. Overcoming obesity: An initial economic analysis. McKinsey Global Institute, 2014. 2016.

5 World Health Organization. Obesity and overweight. Fact sheet number 311. World Health Organisation. Geneva: WHO; 2014.

6 Wang C, Li J, Xue H, Li Y, Huang J, Mai J, et al. Type 2 diabetes mellitus incidence in Chinese: contributions of overweight and obesity. Diabetes Res Clin Pract. 2015;107:424-32. Medline:25649908 doi:10.1016/j.diabres.2014.09.059

7 Chen WW, Gao RL, Liu LS, Zhu ML, Wang W, Wang YJ, et al. China cardiovascular diseases report 2015: a summary. J Geriatr Cardiol. 2017;14:1. Medline:28270835

8 Wang D, Zheng W, Wang S-M, Wang J-B, Wei W-Q, Liang H, et al. Estimation of cancer incidence and mortality attributable to overweight, obesity, and physical inactivity in China. Nutr Cancer. 2012;64:48-56. Medline:22136606 doi:1 $0.1080 / 01635581.2012 .630166$

9 Fang W, Li Z, Wu L, Cao Z, Liang Y, Yang H, et al. Longer habitual afternoon napping is associated with a higher risk for impaired fasting plasma glucose and diabetes mellitus in older adults: results from the Dongfeng-Tongji cohort of retired workers. Sleep Med. 2013;14:950-4. Medline:23831240 doi:10.1016/j.sleep.2013.04.015

10 Foley DJ, Vitiello MV, Bliwise DL, Ancoli-Israel S, Monjan AA, Walsh JK. Frequent napping is associated with excessive daytime sleepiness, depression, pain, and nocturia in older adults: findings from the National Sleep Foundation '2003 Sleep in America' Poll. Am J Geriatr Psychiatry. 2007;15:344-50. Medline:17384317 doi:10.1097/01. JGP.0000249385.50101.67

11 Chen Y, Kartsonaki C, Clarke R, Guo Y, Yu C, Bian Z, et al. Characteristics and correlates of sleep duration, daytime napping, snoring and insomnia symptoms among 0.5 million Chinese men and women. Sleep Med. 2018;44:67-75. Medline:29530372 doi:10.1016/j.sleep.2017.11.1131

12 Xin C, Zhang B, Fang S, Zhou J. Daytime napping and successful aging among older adults in China: a cross-sectional study. BMC Geriatr. 2020;20:2. Medline:31898552 doi:10.1186/s12877-019-1408-4

13 Lan T-Y, Lan T-H, Wen C-P, Lin Y-H, Chuang Y-L. Nighttime sleep, Chinese afternoon nap, and mortality in the elderly. Sleep. 2007;30:1105-10. Medline:17910382 doi:10.1093/sleep/30.9.1105

14 Zhou J, Kessler AS, Su D. Association between Daytime Napping and Chronic Diseases in China. Am J Health Behav. 2016;40:182-93. Medline:26931750 doi:10.5993/AJHB.40.2.3

15 Guo VY, Cao B, Wong CKH, Yu EYT. The association between daytime napping and risk of diabetes: a systematic review and meta-analysis of observational studies. Sleep Med. 2017;37:105-12. Medline:28899519 doi:10.1016/j. sleep.2017.01.018

16 Cao Z, Shen L, Wu J, Yang H, Fang W, Chen W, et al. The effects of midday nap duration on the risk of hypertension in a middle-aged and older Chinese population. J Hypertens. 2014;32:1993-8. Medline:25023156 doi:10.1097/ HJH.0000000000000291

17 Liu Y, Peng T, Zhang S, Tang K. The relationship between depression, daytime napping, daytime dysfunction, and snoring in 0.5 million Chinese populations: exploring the effects of socio-economic status and age. BMC Public Health. 2018;18:759. Medline:29914433 doi:10.1186/s12889-018-5629-9

18 Zhou L, Yu K, Yang L, Wang H, Xiao Y, Qiu G, et al. Sleep duration, midday napping, and sleep quality and incident stroke: The Dongfeng-Tongji cohort. Neurology. 2020;94:e345-56. Medline:31827003 doi:10.1212/WNL.0000000000008739 
19 Loredo JS, Weng J, Ramos AR, Sotres-Alvarez D, Simonelli G, Talavera GA, et al. Sleep patterns and obesity: Hispanic community health study/study of Latinos Sueño Ancillar study. Chest. 2019;156:348-56. Medline:30853108 doi:10.1016/j. chest.2018.12.004

20 Patel SR, Hayes AL, Blackwell T, Evans DS, Ancoli-Israel S, Wing YK, et al. The association between sleep patterns and obesity in older adults. Int J Obes (Lond). 2014;38:1159-64. Medline:24458262 doi:10.1038/ijo.2014.13

$21 \mathrm{Kim}$ M. Association between objectively measured sleep quality and obesity in community-dwelling adults aged 80 years or older: a cross-sectional study. J Korean Med Sci. 2015;30:199-206. Medline:25653493 doi:10.3346/jkms.2015.30.2.199

22 Fang S, Zhou J. Association of daytime napping and diagnosed diabetes in middle-aged premenopausal, middle-aged postmenopausal, and older postmenopausal Chinese women. Am J Health Promot. 2019;33:1107-14. Medline:31167538 doi: 10.1177/0890117119854918

23 Yang Y, Liu W, Ji X, Ma C, Wang X, Li K, et al. Extended afternoon naps are associated with hypertension in women but not in men. Heart Lung. 2020;49:2-9. Medline:31521340 doi:10.1016/j.hrtlng.2019.09.002

24 Furihata R, Kaneita Y, Jike M, Ohida T, Uchiyama M. Napping and associated factors: a Japanese nationwide general population survey. Sleep Med. 2016;20:72-9. Medline:27318229 doi:10.1016/j.sleep.2015.12.006

25 Zhao Y, Hu Y, Smith JP, Strauss J, Yang G. Cohort profile: the China health and retirement longitudinal study (CHARLS). Int J Epidemiol. 2014;43:61-8. Medline:23243115 doi:10.1093/ije/dys203

26 Liu H, Byles JE, Xu X, Zhang M, Wu X, Hall JJ. Association between nighttime sleep and successful aging among older Chinese people. Sleep Med. 2016;22:18-24. Medline:27544831 doi:10.1016/j.sleep.2016.04.016

27 Zhou J, Britigan DH, Rajaram SS, Wang H, Su D. Association between leisure time physical activity preference and behavior: evidence from the China Health \& Nutrition Survey, 2004-2011. BMC Public Health. 2017;17:451. Medline:28511710 doi:10.1186/s12889-017-4386-5

28 Organization WH, editor. National Health and Family Planning Commission of the People's Republic of China. 9th Global Conference on Health Promotion, Shanghai; 2016.

29 Lin D, Sun K, Li F, Qi Y, Ren M, Huang C, et al. Association between habitual daytime napping and metabolic syndrome: a population-based study. Metabolism. 2014;63:1520-7. Medline:25249445 doi:10.1016/j.metabol.2014.08.005

30 Zhou J, Fang S. Association between undiagnosed hypertension and health factors among middle-aged and elderly Chinese population. Int J Environ Res Public Health. 2019;16:1214. Medline:30987361 doi:10.3390/ijerph16071214

31 Zhang L, Liu K, Li H, Li D, Chen Z, Zhang L-l, et al. Relationship between body mass index and depressive symptoms: the "fat and jolly" hypothesis for the middle-aged and elderly in China. BMC Public Health. 2016;16:1201. Medline:27894296 doi:10.1186/s12889-016-3864-5

32 Wang H, Zhai F. Programme and policy options for preventing obesity in China. Obes Rev. 2013;14:134-40. Medline:24102781 doi:10.1111/obr.12106

33 Shen J, Goyal A, Sperling L. The emerging epidemic of obesity, diabetes, and the metabolic syndrome in China. Cardiol Res Pract. 2012;2012:178675. Medline:21961074 doi:10.1155/2012/178675

34 Troisi RJ, Weiss ST, Parker DR, Sparrow D, Young JB, Landsberg L. Relation of obesity and diet to sympathetic nervous system activity. Hypertension. 1991;17:669-77. Medline:2022410 doi:10.1161/01.HYP.17.5.669

35 Sun K, Li F, Qi Y, Lin D, Ren M, Xu M, et al. Sex difference in the association between habitual daytime napping and prevalence of diabetes: a population-based study. Endocrine. 2016;52:263-70. Medline:26487615 doi:10.1007/s12020015-0772-x

36 Lucassen EA, Rother KI, Cizza G. Interacting epidemics? Sleep curtailment, insulin resistance, and obesity. Ann N Y Acad Sci. 2012;1264:110. Medline:22827862 doi:10.1111/j.1749-6632.2012.06655.x

37 Freeman EW, Sammel MD, Liu L, Gracia CR, Nelson DB, Hollander L. Hormones and menopausal status as predictors of depression in women in transition to menopause. Arch Gen Psychiatry. 2004;61:62-70. Medline:14706945 doi:10.1001/ archpsyc.61.1.62

38 Al-Safi ZA, Polotsky AJ. Obesity and Menopause. Best Pract Res Clin Obstet Gynaecol. 2015;29:548-53. Medline:25579233 doi:10.1016/j.bpobgyn.2014.12.002 